\title{
Pricing Ecological Beauty Under Dichotomous Choice Framework: The Case of Taman Negara National Park in Malaysia
}

\author{
Aruna Shantha, A $^{1}$ and Asan Ali, B.G.H. ${ }^{2}$
}

${ }^{1}$ School of Economics, Collage of Business, Northern University of Malaysia, Malaysia.aru@sab.ac.lk

2 School of Economics, Collage of Business, Northern University of Malaysia,Malaysia.aali@uum.edu.my

\begin{abstract}
Taman Negara is Malaysia's premier national park and the largest in the country covering over 4343 square kilometers $(434,300$ hectares) of primary forest, spans across three states Kelantan, Terengganu and Pahang - and is situated in the center of the Peninsula Malaysia. It is home to much wildlife and is a popular tourist attraction to both local and foreign tourists. This study attempts to determine the economic value of Taman Negara National Park by eliciting visitors' willingness to pay (WTP) using contingent valuation method followed by single bounded dichotomous choices. A stepwise backward binary multivariate logistic regression model was used to measure WTP and to determine the factors that influence the variation in WTP. Primary data were obtained from 368 local and foreign visitors who have been interviewed in TN Park. Thestudy found that both local and foreign visitors were willing to pay more than the current charges for entrance permit and nature based activities provided by TN Park. On average visitors are willing to pay for entrance permit RM $16.71(\$ 5.4)$ perperson. The existing rate is RM 1 (\$ 0.32) per person. Beside, WTP for all other activities such as fishing license, camera license, camping fee, canopy walkway and hide fee is much higher than the existing rates. The optimum pricing strategy should be a combination of policy objectives and information gathered from local and foreign visitors on WTP. In conclusion, this study can be used as a tool for revising pricing policies on TN national park in Malaysia.
\end{abstract}

Keywords: Dichotomous choice framework, Willingness to pay, Ecotourism, Pricing policies.

\section{Introduction}

Tourism has undoubtedly become one of the most important and lucrative industries in the world (Boon Chui, et al,, 2010). Morgan (2007),reports that tourist experience is associated with multiple interpretations from social environment and activity component of the overall experiences. Tourism 
is the world's faster growing industry and its faster growing component is ecotourism (Ecotourism Society, 2010). Ecotourism or nature tourism was growing globally four times faster than the tourism industry as a whole in 2011 (The International Ecotourism Society, 2012). In 2011 Malaysia has received 15.8 million tourists and contributed to national revenue by RM 45.8 billion or $6.9 \%$ of GDP in the same year (Board of Tourism Industry in Malaysia, 2012). Within the last decade Malaysian tourism industry promotes a destination, nature-based tourism and it has reflected key trends of tourism industry in Malaysia.

Taman Negara is the most extensive protected area of pristine, lowland, evergreen rainforest in the country. Taman Negara National Park was established in Malaysia in 1938/1939 as the King George V National Park and it was renamed Taman Negara after independence and is a significant geographical feature in peninsular Malaysia (Othman, et al., 2010). It is home to much wildlife and is a popular tourist attraction to both local and foreign tourists. Due to visitors' behavior and various activities performed by park management these beautiful natural resources are being damaged in various ways. Thus, sustainable tourism in its purest sense is an industry committed to making a low impact on the natural environment and local culture. However, existing pricing policies for various activities do not permit to achieve sustainable tourism in TN national Park and it is indispensable to restructure as soon possible (Ministry of Science Technology and the Environment Authority 2010). Many researchers have emphasized the importance of new pricing policy for better management of TN Park. However, establishing a pricing policy for natural resources is not an easy task since park resources are not traded in the market as other commodities. Consequently, non-market valuation techniques were basically identified as tools of pricing the entrance charge.Such a policy can be used for sustainable management of national park and provision of quality products and services for visitors.

\section{Conceptualization and Problem Statement}

Although it is difficult to look for silver linings in the light of the overwhelming tragedy worldwide in tourism industry, there have been some rays of hope and tremendous stories of human endeavor (Dahan, et al., 2010). According to Weaver (2008) ecotourism industry has to generate revenue to financially sustain whilst providing unique experiences and attractions to compete in this blooming industry. Early 1990s ecotourism was a buzzword since it was not properly functioning. However, now tourism industry is the world's fastest growing industry and its faster growing component is ecotourism (Samdin, 2008). According to Dahan et al., (2010) growth rate in this sector has estimated at around 10\%-15\% annually.Tourism is the world's largest and fastest growing industry and this growth will create a stressful situation especially for 
the remaining biologically diverse habitats and indigenous culture, which are often used to support mass tourism (Othman, et al., 2010). Sustainable tourism has become a common slogan after 1990s all over the world across the tourism industry. However, still, mainly in Asian region, sustainable tourism is one of the unachievable objectivesdue to lack of sufficient policies on institutional arrangement for sustainable usage of natural resources and conservation.

The most sufficient institutional arrangement for sustainable resources use and conservation are widely discussed in recent literature (Walker \& Gardner, 1992; Sefton \& Steimberg, 1996; Sell \& Son, 1997). In the case of openaccess and unregulated common property, individual does not get appropriate incentive to act in a social efficient way (Adhikari, 2001). Apestequim and Maier (2006) define common-property resources as a class of resources for which exclusion is difficult and join use involves subtractability. According to Ostrom, et al., (1994) common pool resources are a particular class of goods sharing two characteristics. These are (a) the difficulty of excluding individuals from benefitting from the good, and (b) the subtractability of benefits consumed by one individual from those available to others. Difficulty of exclusion and subtractability create challenges that groups of appropriators need to overcome if the resources are to be sustained. A self- governed common-pool resource is one where actors, who are major appropriators of the resource, are involved over time in marking and adapting rules within collective -choice arenas regarding the inclusion or exclusion of participants (Montgomery \& Bean , 1999).

Recent literature on common property resource management indicates that sustain the environment resources do not depend on a particular structure of property rights. Rather it depends on a well-specified property rights regime and a congruence of that regime with its ecological and social context (Hanna \& Munasingha, 1995). Bromley (1991) considers the open access situation as a resource regime in which there are no property rights. Because there are no property rights in an open access situation, it is logically inconsistent to assert often do "everybody's property is no nobody's property" (Bromely, 1991). Individuals have both privileges and no rights with respect to use rates maintenance of the assets. This is the situation of mutual privilege and no rights, no user has the right to preclude use by any other party (Bromely, 1991).

Common pool resources managed under common property resources management regimes, share some important characteristic (Adhikari, 2001). Natural product like trees, water, wildlife, are subtractable and in most cases exclusion will be problematic and costly. An individual used more means less remaining for others. These resources are therefore potentially subject to depletion or degradation (Varughess, 1999). 
Public goods are goods or services that can be consumed by several individuals simultaneously without diminishing the value of consumption to any one of the individuals. The key characteristics of public goods in non-rivalry, which is the multiple individuals, can consume the same good without diminishing the value (Montgomery \& Bean, 1999). Pure public goods also have the characteristics of non-excludability, that is, an individual cannot be prevented from consuming the good whether or not the individual pays for it (Benson, 1994). Due to non-rivalry and non- excludability, public goods cannot be so easily and efficiently priced. Since it is difficult to price, inefficiency arises in the provision of public goods. In terms of public goods the market price is no longer an efficient mechanism, because the stock of public goods is never "consumed away" (Benson, 1994). The reason inefficiency arise in providing public goods is that, unlike price, quantity is not an effective market mechanism. For given quantity, individual will not automaticallyself-select their optimal price, but will instead wish to pay the lowest price possible when they cannot be excluded from consuming the good (Beito \& Smith, 1990).

In economics, the term "market failure" mainly incorporated with provision of public goods and non-excludability is the main cause of market failure involving public goods (Apesteguia, et al., 2006). Private market often underprovides non-excludable public goods, because individuals have the intensive to free ride, or not to pay for the benefit they receive from consuming the public goods (Cowen, 1992). With free- rider problem, private firm cannot earn sufficient revenues from selling the public goods to induce them to produce the socially optimal level of public good (Montgomery \& Bean , 1999).

It is no clear explanation on national park, which should be cater under public goods or common pool resources. Most literature, such natural resources considered as public goods since those are functioning under public management (Foldvary, 1994). Whether it is common-pool resources or public goods, market mechanism is nota good way to value the resources (Cowen, 1992). So now main question is to what extent the price of entrance permit and other activities organized by park management in Taman Negara National Park can be guided byfree market forces or require some extra management to serve social objective or sustainable objectives. According to number of literature, visitor's willingness to pay under contingent valuation method is most popular and relevant non-market valuation approach to measure the economic value of such natural resources.

\section{Objectives of the Study}

The main objective of this research paper is to propose an appropriate pricing policy for entrance permit to TNNP which has been implemented since 1970s. Beside, researchers have attempted to identify the important socio-economic 
factors behind the willingness to pay (WTP) decision on entrance permit and other nature based activities carried out by TNNP among local and foreign visitors.

\section{Materials and Methods}

The theoretical model of the study is based on standard microeconomics principles and empirical workcited in the literature review section. Contingent Valuation Survey (CVS) stimulates a market for a non-market good and obtains a value for the good (Wedgwood \& Sansom, 2003). CVS is a unique method that can estimate the value of non-market goods such as protected area resources (Samdin, 2008). Contingent valuation elicitation questions may be open-ended or closed-ended. In an open-ended question the respondent is asked to state the maximum amount that he or she is willing to pay for the good or service that is being valued (Arrow, et al., 1993). Under closedended contingent valuation CV question or "dichotomous choice" approach the respondent is asked whether he or she is willing to pay a specific amount presented as the value of the improved service (Gunathilaka, et al., 2007). In this study researcher applied dichotomous choice approach and since dependent variables were collected binary data, logistic model was applied to estimate WTP. There are many activities provided by the park, specifically, fishing, camping, canopy and hide. Visitors can enjoy all those activities by taking license under specific payment. However, in this study researcher applied dichotomous choice framework with logistic model for measuring only the entrance permit to the park. The reduced form of a typical logistic probability model for willing to pay on proposed entrance permit and factors effecting for their decision can be written in the following form:

$\operatorname{Pr}\left[\mathrm{Y}_{\mathrm{t}=1}\right]=$
$\operatorname{Pr}\left[\mathrm{Y}_{\mathrm{t}=1}\right]=$

Where,

$Y \quad=$ Agreed or not for proposed specific amount for entrance permit (Proposed bid levels were greater than the current entrance charge)

$1=$ willing to-pay, $0=$ not willing-to-pay

$B I D(X 1)=$ Visitors Bid level for entrance permit (RM per person)

$S \quad=$ Visitors Socio-economic characteristics

INC (X2) = Monthly Income of visitor MR (Malaysian Ringgit)

NIS $(X 3)=$ No of income sources

$\operatorname{VLT}(X 4)=$ Visitors leisure time (holidays) per month; 
EK (X5) = Existing knowledge on natural resources; (1) Good, (0) Otherwise NNTN (X6) = No of nights spent in park during their visiting period NAU (X7) = No of activities used after entering the park (Fishing, Camping, Canopy, Hide)

$N T(X 8)=$ No of times visited the park.

$F=$ Demographics characteristics

Age $(X 9)=$ Years

SEX $(X 10)=(1)$ Male; (0) female

$T V(X 11)=$ Type of Visitors; (1) = Foreign, (0) = Local

EDC (X12) = Education: Respondents education level (lastly reached grade)

\section{Sampling Framework and Data Gathering Tools}

This study undertakes two phases, firstly a preliminary meeting and discussion with the relevant officers on existing pricing policies and propose new bidding strategies under the research. Secondly a questionnaire was designed to gain information on WTP in this study. It was sensibly developed following seven pillars of CV survey which was introduced by NOAA panel (Arrow et al., 1993). The survey questionnaire was chosen because it encouraged high response rate and was suitable for complex questions. The questionnaire was divided into two sections: socio-economic characteristics of visitors and paying capabilities for entrance permit and services provided by TN National Park. Willingness to pay for National Park was covered in second section of the questionnaire. To discover the willingness to pay for TN Park from selected visitors, we applied the bidding game approach which involved three different prices (low, medium and high) for entrance permit and other services. First, higher price was proposed and responses were checked. If they refused at the first bidding level, second one or third one was proposed. Three bidding levels were proposed to the customer and he agreed with the most suitable one.Systematic sampling procedure was used atpersonal interviews. Every fourth visitor who exits from the park was chosen as a sample since they have some value judgment of existing natural resources and activities in the park.A personal interview was conducted separately among Malaysians and international visitors. The survey was conducted at various locations of the park during the period of 15-28 January 2012. The survey results in total of 368 visitors, 235 internationals and 133 Malaysians. 


\section{Results, Discussion and Conclusion}

\section{Visitors' profiles}

More than half (59.3\%) of the visitors were international and the rest (40.7\%) were Malaysian. Out of 368 international visitors, $(17 \%)$ were from Germany, followed by Netherland (16\%), Australia (12\%), Singapore (10\%), Thailand $(9 \%)$, France (9\%), Spain (7\%), and England (4\%). The remaining was from Switzerland, USA, Indonesia and India.

The majority of visitors were between 30-45 year of age (48\%) and 20-29 years of age $(42 \%)$ and insignificant percentage above 65 years old (2\%). Balance was below 20 years old (8\%). By gender, the majority of foreign visitors were $(64.8 \%)$ males and more than half were married $58.7 \%)$. According to the survey, $52 \%$ of international visitors' monthly income was more than US\$ 1500 and balance was below US\$ 1500 .

\section{Visitors Characteristics}

However, only $28 \%$ of Malaysian visitors were exceeding US\$ 1500 income level per month and the balance was below the referenced level. In terms of educational background $35 \%$ of visitors (out of total) had completed secondary education. Beside $29 \%$ and $18 \%$ visitors had reached basic degree and master qualification respectively. According to Table 1 majority of Malaysian visitors (64) had taken information on TNNP from their friends and relatives, while majority of international visitors (178) obtained information from travel guidebook. Travel agent, travel brochure and internet were the other sources from which the foreigners had obtained information on TNNP. Both local and foreign visitors mainly associated TNNP with wildlife (127 locals and 211 foreigners) and rainforest was the second best selection of both categories. Watching wild animals was the main reason for visiting TNNP by locals as well as foreigners. Local visitor's most popular type of transportation to TNNP was public bus $(26.2 \%)$ and international visitor's popular transportation mode was tour bus (47.1\%). Chalets were the most popular type of accommodation at TNNP by locals $(59.7 \%)$ and foreigners $(66.9 \%)$. Both parties had chosen hostel as second option for accommodation. More than half of both locals and foreign visitors stayed at TNNP an average of two nights and less than 10\% visitors stayed at TNNP more than two nights. 
Table1:Characteristics of Visitors

\begin{tabular}{|c|c|c|}
\hline Characteristics & $\begin{array}{c}\text { No of responses } \\
\text { (Malaysians) } \\
n=133\end{array}$ & $\begin{array}{c}\text { No of responses } \\
\text { (Internationals) } \\
\quad \mathbf{n}=\mathbf{2 3 5}\end{array}$ \\
\hline \multicolumn{3}{|c|}{ Source of information (frequency) } \\
\hline Relations and friends & 64 & 23 \\
\hline Travel guidebook & 56 & 178 \\
\hline Travel agent & 32 & 126 \\
\hline Travel brochure & 29 & 121 \\
\hline Internet & 22 & 87 \\
\hline Advertisement & 12 & 64 \\
\hline \multicolumn{3}{|c|}{ TNNP Characteristics (frequency) } \\
\hline Rainforest & 121 & 178 \\
\hline Scenic beauty & 89 & 145 \\
\hline Recreation & 76 & 165 \\
\hline Wildlife & 127 & 211 \\
\hline Flora and fauna & 56 & 78 \\
\hline Aboriginal & 39 & 58 \\
\hline \multicolumn{3}{|l|}{ Reasons for visiting (frequency) } \\
\hline Holidays & 121 & 198 \\
\hline Relaxing & 98 & 157 \\
\hline See the natural beauty & 105 & 178 \\
\hline Changing daily life circle & 111 & 123 \\
\hline Watching wild animals & 127 & 212 \\
\hline Learning environmental things & 56 & 78 \\
\hline For getting experiences & 24 & 90 \\
\hline \multicolumn{3}{|l|}{ Mode of transportation (\%) } \\
\hline Public bus & 26.2 & 2.1 \\
\hline Train & 13.1 & 4.6 \\
\hline Private car & 21.2 & 21.1 \\
\hline Tour bus & 25.1 & 47.1 \\
\hline Flight & 1.5 & 8.3 \\
\hline Boat & 11.6 & 8.2 \\
\hline Taxi & 1.3 & 8.6 \\
\hline \multicolumn{3}{|l|}{ Accommodation (\%) } \\
\hline Chalet & 59.7 & 66.9 \\
\hline Hostel/dorm & 25.9 & 17.8 \\
\hline Camping & 9.1 & 5.3 \\
\hline Hide & 4.1 & 3.5 \\
\hline Cave & 1.2 & 6.5 \\
\hline \multicolumn{3}{|l|}{ Number of nights (\%) } \\
\hline$<1$ & 38.5 & 26.8 \\
\hline $1-2$ & 55.7 & 64.5 \\
\hline$>2$ & 5.8 & 8.7 \\
\hline
\end{tabular}

Source: Field Survey - 2012

\section{Mean Value of WTP for different Services at TNNP}

This section analyses the willingness to pay for various services carried out by TNNP, especially for Fishing camera license, canopy walkway, camping fee 
and hide. Important to note that, existing charges of all activities provided by park management were lesser than the willing to pay price of such services by sample visitors. These results propose policy makers to reconsider the current pricing policies at TNNP in achieving sustainable tourism industry.

Table 2: Mean value of WTP for different Services at TNNP

\begin{tabular}{llr}
\hline Type of service & Existing charges & Mean Value of WTP(RM) \\
\hline International Visitors & & \\
& & \\
Fishing License & RM 10 per person & $12.60(4.8)$ \\
Camera License & RM 5 per camera & $8.5(3.7)$ \\
Canopy walkway & RM 5 per person & $10.8(5.9)$ \\
Camping fee & RM 1/day per person & $5.5(2.7)$ \\
Hide & RM 5/night per person & $12.5(4.1)$ \\
& & \\
Malaysian Visitors & & \\
& & \\
Fishing License & RM 10 per person & \\
Camera License & RM 5 per camera & $10.5(5.3)$ \\
Canopy walkway & RM 5 per person & $5.5(2.1)$ \\
Camping fee & RM 1/day per person & $7.8(3.2)$ \\
Hide & RM 5/night per person & \\
\hline
\end{tabular}

Note: Existing pricing was taken from TN park management. 1US\$ = RM 3.1. Mean values were derived based on willingness to pay questions for each activates.

\section{Contingent Valuation of Entrance Permit}

Under this section, respondents were asked two questions. First, respondents were asked whether they werewilling to pay the existing entrance permit charge presented "in principle" for TNNP as entrance permit. Thus, first question was a dichotomous choice question or closed-ended question. If the answer was "Yes" moved to next part of the questionnaire. Where the answer was "No" such respondents post to discover their opinion on 'disagreed to paying' (even though they paid) the proposed entrance charge. If the answer was "Yes" such respondents post to discover their opinions on the level of paying for TNNP. At the beginning enumerators proposed medium level of fee and if they accepted suddenly, proposed higher bidding rate. Conversely, as they rejected medium bidding rates then post to lower one. This approach is called "Bidding Game" and used three bidding rates since the study covered a reasonable sample. Proposed entrance charges were developed by reviewing existing pricing policies and recent literature on sustainable tourism management. Surprisingly, majority of both local and foreign visitors agreedwith the proposed bidding rates for entrance permit to TNN Park. However, $15 \%$ international visitors 
and $19 \%$ Malaysian visitors refused to pay onthe proposed entrance schemes due to various reasons.

Generally, majority of the visitors who disagreed stressed that the existing poor facilities did not justify the current paying scheme. More specially, poor natural resource management practices and insufficient services were highlighted as the main reasons. Howeveralmost all visitors were aware that the government was spending considerable amount of money for natural resource management. Yet under the existing situation they refused to pay any additional charge above the existing level. Out of 368 respondents 360 agreed to paythe revised rate for the permitunder the proposed pricing scheme. A parametric logistic probability model was employed to estimate central tendency measures of WTP for entrance permit (Hanemann, 1984; Gunathilaka, et al., 2007). To calculate the mean value of WTP for entrance permit, divide the coefficient on -constant (i.e., 4.111) by the coefficient on BID (i.e., 0.246) and multiply by -1 (Hair Jr, et al., 2010). The study gets a value of about 16.71, which is the mean WTP for the overall sample or total visitors. Similar procedure was applied for measuring WTP for local and foreign visitors.

The results of WTP for entrance permit are presented in Table 3. As estimated parametric logistic model the mean value of WTP for entrance permit is RM 16.71 for totalvisitors. However, that value for Malaysian visitors was RM 8.61 and for international visitors it was RM 21.78. It is important to note that almost all the visitors were willing topay a much higher charge for the entrance permit to TNNP than present entrance charges.

Table 3: Mean value of WTP for Entrance Permit

\begin{tabular}{|c|c|}
\hline Statistics & $\begin{array}{c}\text { WTP for Entrance Permit } \\
\text { (RM/person) }\end{array}$ \\
\hline Mean WTPa (Total visitors) & 16.71 \\
\hline Standard error & 6.7 \\
\hline No of observations & 368 \\
\hline Mean WTPa (Malaysian Visitors)) & 8.61 \\
\hline Standard error & 3.98 \\
\hline No of observations & 133 \\
\hline Mean WTP ${ }^{\mathrm{a}}$ (International visitors) & 21.78 \\
\hline Standard error & 8.78 \\
\hline No of observations & 235 \\
\hline
\end{tabular}




\section{Factors Explaining WTP for Entrance Permit}

A stepwise backward binary multivariate logistic regression model was applied to determine the key factors associated with Willing ToPay decision of selected 368 local and international visitors to TNNP (Table $4 \& 5$ ). Here, the socio-economic and demographic characteristics of visitors were considered. Initial model was run with 12 explanatory variables; however after the $7^{\text {th }}$ iteration model was selected, it was possible to determine ten key factors which mainlyinfluenced respondent's decisions. Selected variables, their beta values and the level of significance of each estimated beta values are as follows:

Table 4: Important Indicators of the estimated logistic Model - Total Visitors

\begin{tabular}{lccccc}
\hline Variables in the equation & $\boldsymbol{\beta}$ & Std.Error & Wald & Sig & $\operatorname{Exp(\beta )}$ \\
\hline BID(X1) & 0.246 & 0.157 & 16.781 & 0.001 & 1.279 \\
INC(X2) & 0.558 & 0.343 & 9.562 & 0.012 & 1.823 \\
NIS(X3) & 0.601 & 0.319 & 5.321 & 0.013 & 1.824 \\
VLT(X4) & 0.279 & 0.131 & 5.098 & 0.013 & 1.322 \\
EK(X5) & 0.247 & 0.190 & 4.776 & 0.016 & 1.280 \\
NNTN(X6) & 0.011 & 0.002 & 6.582 & 0.012 & 1.011 \\
NAU(X7) & 0.458 & 0.259 & 11.234 & 0.002 & 1.580 \\
TV(X11) & 0.389 & 0.283 & 6.287 & 0.011 & 1.475 \\
EDU(X12) & 0.381 & 0.121 & 4.997 & 0.017 & 1.463 \\
CONSTANT(X11) & -4.111 & 1.193 & 22.085 & 0.000 & 0.016
\end{tabular}

Note: $\beta=$ Logistic coefficient, $\operatorname{Exp}(\beta)=$ exponentiated coefficient

Table 5: Important Indicators of the Estimated Logistic Model - Foreign Visitors

\begin{tabular}{lccccc}
\hline Variables in the equation & $\boldsymbol{\beta}$ & Std.Error & Wald & Sig & $\operatorname{Exp(\beta )}$ \\
\hline BID(X1) & 0.311 & 0.172 & 21.021 & 0.001 & 1.279 \\
INC(X2) & 0.766 & 0.456 & 9.562 & 0.001 & 2.151 \\
NIS(X3) & 0.812 & 0.331 & 5.321 & 0.013 & 2.272 \\
VLT(X4) & 0.397 & 0.156 & 5.098 & 0.013 & 1.487 \\
EK(X5) & 0.299 & 0.190 & 4.776 & 0.016 & 1.348 \\
NNTN(X6) & 0.311 & 0.200 & 6.582 & 0.012 & 1.364 \\
NAU(X7) & 0.558 & 0.359 & 11.234 & 0.002 & 1.747 \\
EDU(X12) & 0.481 & 0.221 & 4.997 & 0.017 & 1.617 \\
CONSTANT(X11) & -6.774 & 2.989 & 24.055 & 0.001 & 0.001
\end{tabular}

Note: $\beta=$ Logistic coefficient, $\operatorname{Exp}(\beta)=$ exponentiated coefficient 
Researcher applied three separate logistic models for foreign visitors, Malaysian visitors and total visitors. The summary statistics of the goodness of fit and estimated coefficients are presented in Table no 6, 7 and 8. However, the socio-economic impacts on Willingness To Pay were discussed based on total visitors' model (Table no. 6).In this final model almost all the variables except constant have positive signs, indicating the positive relationship between dependent variables and predicted probability. Among selected explanatory variables umber final model, visitor's income was the most influential variable for Willingness To Pay decision. As visitors income increased, they have shown higher commitment to new package of entrance permit. Secondly, those who have much more leisure time (holidays per month) they have reflected higher obligation for WTP than others. Thirdly, visitors, who have had more activities at the park, have shown higher commitment on Willing To Pay for new package, Further, as visitor's educational level and existing knowledge on natural resource management increased, WTP for new package has been increased. This result indicates the universal fact that the knowledge enhances the awareness in value of natural environment. Beside, foreigners were more committed to new entrance package than local visitors. Finally, as number of nights spent in park during their visiting period and number of activities used after entering the park increased WTP for TNNP were increased. However, Age, sex and number of times visited the parkwere rejected from the final model, since those variables did not reflect much variation of WTP decision. All those results were consistent with theoretical expectation and empirical findings.

Table 6: Important Indicators of the Estimated Logistic Model - Malaysian Visitors

\begin{tabular}{lccccc}
\hline Variables in the equation & $\boldsymbol{\beta}$ & Std.Error & Wald & Sig & $\operatorname{Exp}(\boldsymbol{\beta})$ \\
\hline BID $(X 1)$ & 0.196 & 0.121 & 14.631 & 0.001 & 1.216 \\
INC(X2) & 0.571 & 0.232 & 8.265 & 0.002 & 1.770 \\
NIS $(X 3)$ & 0.421 & 0.223 & 4.211 & 0.016 & 1.523 \\
VLT(X4) & 0.297 & 0.163 & 5.003 & 0.013 & 1.346 \\
EK(X5) & 0.188 & 0.145 & 4.209 & 0.016 & 1.207 \\
NNTN(X6) & 0.231 & 0.102 & 6.992 & 0.012 & 1.259 \\
NAU(X7) & 0.441 & 0.262 & 9.431 & 0.002 & 1.554 \\
EDU(X12) & 0.346 & 0.121 & 4.023 & 0.016 & 1.413 \\
CONSTANT(X11) & -1.687 & 1.001 & 11.085 & 0.002 & 0.185 \\
\hline
\end{tabular}

Note: $\beta=$ Logistic coefficient, $\operatorname{Exp}(\beta)=$ exponentiated coefficient

12

\section{Magnitude of the Relationships}

To determine how much the probability will change given a one-unit change in the independent variable or change in WTP in this study. In this study there were two type of independent variables: metric and non-metric variables (Dummy). Thus, magnitude of the relation was described under two sections. 


\section{Metric Independent Variable}

The most direct method of assessing the magnitude of the change in probability due to each metric independent variable is to examine the exponentiated coefficient (Joseph F, et al., 2010). The exponentiated coefficient minus one into 100 equals the percentage changes in odds due to one unit change in independent variable.

According to Table 7, all estimated exponentiated coefficients are greater than one except interceptand it denotes positive relationship with dependent variable as concluded previously. According to the value of percentage change in odds, a one -unit change in visitor's income will increase the odds by 82.3 $\%$. It was evident that higher income holders were extremely committed to paying higher Taman Negara price than low income holders.

Table 7: Percentage Change in Odds in Metric Variables (Total visitors)

\begin{tabular}{lccc}
\hline \multicolumn{1}{c}{ Variables } & $\begin{array}{c}\text { Percentage } \\
\text { change in Odds }\end{array}$ & $\operatorname{Exp}(\boldsymbol{\beta})$ & Significance \\
\hline BID(X1) & 27.9 & 1.279 & 0.001 \\
INC(X2) & 82.3 & 1.823 & 0.012 \\
NIS(X3) & 82.4 & 1.824 & 0.013 \\
VLT(X4) & 32.2 & 1.322 & 0.013 \\
NNTN(X6) & 1.1 & 1.011 & 0.012 \\
NAU(X7) & 58.0 & 1.580 & 0.002 \\
EDU(X12) & 46.3 & 1.463 & 0.017
\end{tabular}

Note ${ }^{\mathrm{a}}=\mathrm{e}_{\mathrm{i}}^{\mathrm{b}}-1^{*} 100$, Source: Logistic Regression Output

A one unit change (increased) in visitor's leisure timeleads to increase the odds by $32.2 \%$. Thus, visitor's leisure time is more effective factor behind new entrance package. Further, the more the park activities are used by visitors, themore encouraged they are, for paying higher rate as entrance permit. Beside, as number of income sources and the level of education increased visitors WP would alsoincrease.

\section{Nonmetric Independent Variables - Total Visitors}

The exponentiated coefficients are the best means of interpreting the impact of the dummy variable but are interpreted differently from the metric variable (Joseph F, et al., 2010). Exponentiated coefficient represents the percentage of the odds ratio of visitors who agreed to pay the proposed entrance package compared to disagreed visitors. Because 1 stated for agreed visitors and 0 stated disagreed visitors in the model. Thus, summarized nonmetric coefficients are given in Table 8. 
Table 8:Magnitudes of Nonmetric Variables (Total Visitors)

\begin{tabular}{lcc}
\hline \multicolumn{1}{c}{ Variable } & $\operatorname{Exp}(\boldsymbol{\beta})$ & Significance \\
\hline $\mathrm{EK}(\mathrm{X} 5)$ & 1.280 & 0.016 \\
$\mathrm{TV}(\mathrm{X} 11)$ & 1.475 & 0.011 \\
\hline
\end{tabular}

Source: Logistic Regression Output

Among exponentiated coefficients, types of visitors have been highly associated with the willing to pay decision. Types of visitors' coefficient are 1.475 means that, foreign visitors have 47.5 percent higher odds than Malaysian visitors $(1.475-1=0.475)$ (Table 9). Simply, foreign visitors are 47.5 percent higher enthusiastic for paying proposed entrance price than Malaysian visitors. Second important nonmetric independent variable is existing knowledge on natural resource management. Those visitors who were withgood knowledge on natural resource management have reflected more commitment to WP for new entrance package than others.

Table 9: Overall Model Fit

\begin{tabular}{lll}
\hline Change in -2LL (-2 Log Likelihood) & Change & Significance \\
\hline From Base Model & 257.888 & 0.000 \\
From Prior Step & 6.357 & 0.808 \\
\hline
\end{tabular}

Source: logistic Regression Output

Note: Initial -2 Log Likelihood is 361.098 and with final step it is 103.21

\section{Assessing Overall Model Fit}

The first statistical measure is the chi-square test for the change in the -2LL value from the base model. In this exercise the $-2 \mathrm{LL}$ value has reduced from the based model value of 361.098 to 103.21 , a decrease of 257.888 as shown in table 8 . This increase in model fit was statistically significant at 0.000 levels. However the -2LL value has reduced from prior model by 6.357 (Table 10). This increase in model fit was significant at the 0.808 level.

Table 10: HosmerLemeshow Test

\begin{tabular}{ccc}
\hline Step & Chi-Square & Significance \\
\hline 1 & 3.127 & 0.912 \\
2 & 2.211 & 0.965 \\
3 & 3.587 & 0.802 \\
\hline
\end{tabular}

Source: logistic Regression Output 


\section{Hosmer and Lemeshow Test}

Hosmer and lemeshow test also measure the overall fit of the model. This test measures the correspondence of the actual and predicted values of the dependent variable. The better model fit is indicated by a smaller difference in the observed and predicted classification. In this case significance level has reduced to 0.802 as shown in table 10. A non-significant value indicating that the model fit is acceptable while does not remain significant difference between actual and expected values.

\section{Pseudo $\mathbf{R}^{2}$ Measures}

There are three $\mathrm{R}^{2}$ measures in logistic regression model as in Table 11 . All those indicators measure based on the reduction in the $-2 \mathrm{LL}$ value. In combination, all these three measures the variation of odds due to selected explanatory variables and it represent overall model fit. In this case Pseudo $\mathrm{R}^{2}$ is 0.741 indicating that the logistic regression model accounts for at least $74 \%$ variation of dependent variable. The hit ratio is $82.3 \%$ n indicates that the regression model predictive capacity is more than $89 \%$. (89.3\% of analysis sample correctly classified).

Table 11: Measures of PseudoR ${ }^{2}$

\begin{tabular}{|l|c|}
\hline Measures of $\mathbf{R}^{\mathbf{2}}$ & Value \\
\hline Cox and Snell R & 0.556 \\
Nagelkerke R & 0.831 \\
Pseudo R & 0.741 \\
Hit Ratio $^{* *}$ & $89.3 \%$ \\
\hline
\end{tabular}

Source: Logistic regression Output

Note: ** Percentage correctly classified.

\section{Conclusions and Policy Implications}

Dichotomous choice framework is a unique method that can be applied to measurethe economic value of non-market goods including natural resources (Easter, et al., 1997). The study found that both local and foreign visitors were willing to pay more than the current charges for entrance permit as well as all activities provided by TN Park. On average visitors were willing to pay for entrance permit RM 16.71 (\$5.4) per person, while the existing rate wasRM $1(\$ 0.32)$ per person for both Malaysian and foreign. Foreigners were more committed on WTP for TN Park than locals; Foreigners WTP was RM 21.78 (\$ 7.0) and locals were RM 8.61 (\$ 2.8) per person. In fact, those WTP values were good indicators for economic value of ecological beauty at Taman Negara National Park. Beside, WTP for all other activities such as fishing license, camera license, camping fee, and canopy walkway and 
hide fee are were much more than the existing price. In conclusion, this study can be used as a tool for revising pricing policies on $\mathrm{TN}$ national park in Malaysia. Such new pricing scheme would help enhance park revenue and it can contribute to proper maintenance of the park and protection of the natural environmental in the park. The optimum pricing strategy should be a combination of information gathered from local and foreign visitors on WTP. Furthermore, this study found that the foreign visitors were more willing to pay for nature based activities than local visitors. Thus, park management can impose price discrimination strategy between foreigners and locals to enhance park revenue. In conclusion, the outcome of this study can be used as a tool for revising existing pricing policies on nature based activities at TN national park in Malaysia. Further, policy makers can identify the range of price increase of those activities without damaging the local and foreign tourism market at TN national park.

\section{References}

Adhikari, B. (2001). Literature review on the economics of common property Resources - Project Report for NRSP Project R 7858. York: University of York.

Apesteguia, J., Frank, P., \& Rigaud, M. (2006). The Role of Rivalry:Public Good Versus Common-Pool Resources. Journal of Conflict Resolution, 50(2), 646-663.

Apestequim, J., \& Maier, R. (2006). The Role of Rivelry:Public good versus Common-poll Resources. Journal of Conflict Resolution, 50(1), 646-663.

Arrow, K., Solow, R., Portney, P., E.E, L., Radner, R., \& Schuman, H. (1993). Report of the NOAA panel Contingent Valuation. 58(10), 4601-4614.

Beito, D, \& Smith, B. (1990). The Formation of Urban Insfrastructure through Nongovernment planing: The private places of St. Louis, 1869-1920. Journal of Urban History, 16(3), 263-303.

Benson, B. (1994). Are public Goods Really Common Pools? Consideration of the Evaluation of policing and Highways in England. Economic Inquiry, 32(2), 249-227.

Board of Tourism Industry in Malaysia. (2012). Market Research Report. Kuala Lumpur: Malaysian Tourism Bord. 
Boon Chui, C. T., Rahim, F. A., \& Hassan, F. H. (2010). Exploring Tourist Experiencescape and servicscape at Taman Negara National Park in Malaysia. International Journal of Trade, Economics and Finance, 1(1), 28-31.

Bromley, D. (1991). Environment and Economy: Property Rights and Public Policy. Oxford: Oxford University Press.

Cowen, T. (1992). Public Goods and Market Failure: . New Brunswick N.J: Transactions Publication.

Currarini, Sergio; Matthew, O; Jackson, Paolo Pin (2008). An Economic Model of Friendship: Homophily Minorities and Segregation. (January 2007, Revised July 29, 2008). (Online Open Access).

Dahan, H. M., Ahmad, N., \& Ho, c. S. (2010). Crisis Management at Taman Negara National Park, Kuala Tahan, Pahang, Malaysia. International Journal of Trade,Economics and Finance, 1(1), 24-27.

Easter, K., Becker, N., \& Tsur, Y. (1997). "Economic Machanism for managing WaterResources:Pricing,Permits and Market". in A.K Biswas (ed.)Water Resource Invironmental Palnning, Management and Development. New York: McGraw-Hill.

Ecotourism Society. (1998). Ecotourism Statistical Fact sheet: Generlal Tourrism Statistics. Washington DC: Ecotourism Society.

Foldvary, F. (1994). Public Goods and Private Communities: The market Provisions of Social Services . Aldershot, England: Edward Elgar.

Gunathilaka, H., Chen, J., Pattanak, S., \& Chde, K. (2007). Good practices for Estimating Reliable williness-to-pay value in the water supply and sanitation sector- ERD technical notes series , No 23. Phillipines: Asian Development Bank, Economic and Research Department.

Hair Jr, J., William , C., Barry, J., \& Rolph, E. (2010). Multivariate Data Analysis (Seventh Edition). New Jersey: Pearson.

Hanemann, W. (1984). Welfare Evaluations in Contingent Valuation Experiments with Discreate Responses. Americal Journal of Agricultural Economics, 66(2), 332-41.

Hanna, S., \& Munasingha, M. (1995). An Introduction to Property Rights and the Environment: Social and Ecological Isseus. Washington D.C: International Institute of Ecological Economics and The World Bank. 
Joseph F, H., Black, W., Barry, J., \& Rolph E, A. (2010). Multivariate Data Analysis (Seventh Edition). Pearson Prentice Hall.

Ministry of Science Technology and the Environment. (2010). Assessment of Biological Diversity in Malaysia: Contry Study of Biological Diversity. Kuala Lumpur: MOSTE.

Montgomery, M., \& Bean , R. (1999). Market Failure, Government Failure, and the Private Supply Public Goods: The Case of Climate-Controlled Walkway Network. Public Choice, 99, 403-437.

Morgan, M. (2007). We are not the Barmy Army: Reflections on the sports tourist experiences. International Journal of Tourism Research, 9(5), 361-372.

Ostrom E, Grandner, R., \& Walker, J. (1994). Neither Market nor states:Linking Tranformation Processin collective action arenas. Cambridge: Cambrudge University Press.

Othman, N. A., Anwar, N. M., \& Kain, L. (2010). Sustainability Analysis: Various Ipact on Taman Negara, pahang, malaysia. Journal of Tourism,Hospitality \& Culnary Arts, 3(2), 67-80.

Samdin, Z. (2008). Willingness to Pay in Taman Negara: A Contingent Valuation Method. International Journal of Economic and Management, 2(1), 81-94.

Sefton, M., \& Steimberg, R. (1996). Reward Structure in public good Experiments. Journal of Public Eonomics, 60(1), 263-287.

Sell, J., \& Son, Y. (1997). Comparing public goods with Common-Pool Resources: Three experiments. Social Psychology Quartely, 60(2), 118137.

The International Ecotourism Society. (2007). Ecotourism Fact sheet. Retrieved March 03, 2012, from http:// international ecotourism society.

Varughess, J. (1999). Village Bureaucrats and Forest in Nepal: Desiging Governmance for Complex Resources, PhD Dissertation. Washiton: Indiana University Press.

Walker, J., \& Gardner, R. (1992). Probabilistic Destruction of Common- Pool Resources: Experiment Evidence. Economic Journal, 102(2), 212-234. 
Weaver, D. (2008). Ecotourism. Melborn: John \& Wiley and Sons.

Wedgwood, A., \& Sansom, K. (2003). Willing-to-Pay Surveys: Streamlined Approach. Loughborough University. U.K: Water Engineering \& Development Centre. 
